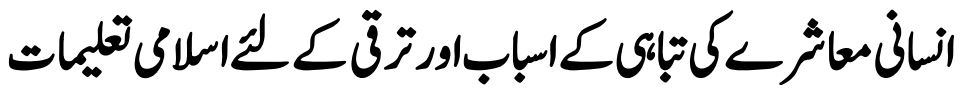

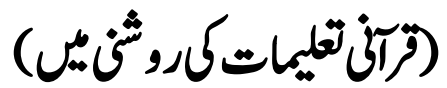

\section{The fall of Human societies: Causes and Solutions \\ (In the Light of Quranic Teachings)}

\begin{abstract}
The development and accomplishment of Islamic societies is a matter of great importance. The significance and the need of this issue is not only a natural desire but it is the requirement of human societies. To proceed on the way of accomplishment and progress is a natural desire that Allah Almighty has inserted into human beings. The individual perfection of character and person is guaranty of an exemplary developed society that is the ultimate wish of Islam.In this regard, Allah Almighty has described the causes of the destruction of the nations of earlier prophets. Such narrations are shown up to the coming nations so that they could avoid such negligence. Quran has described these events as lessons to achieve the perfection in personal as well as in collective, social life.Today the development of science and technology is considered the perfection and the height of the progress of mankind. But the concept of human progress and perfection is different in the light of holy Quran. Islam considers these developments the part of human necessities in their worldly lives not the ultimate achievement that is required for a society that possesses human characteristics. According to Quran the respect of human values is the dire need of a peaceful and privileged society.
\end{abstract}

Key Words: Society, destruction, accomplishment, human values, causes.
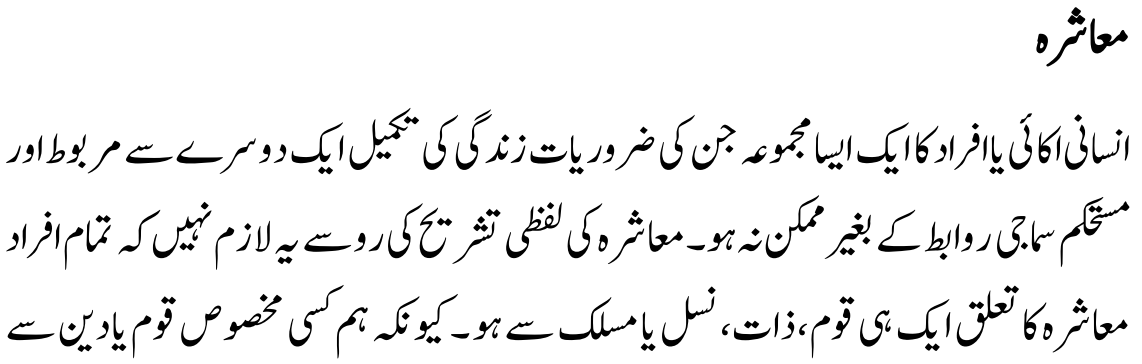

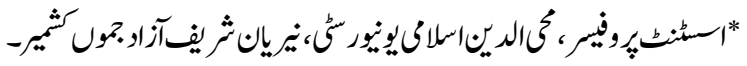

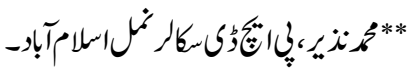




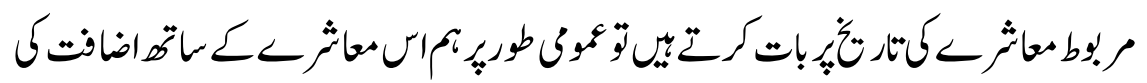

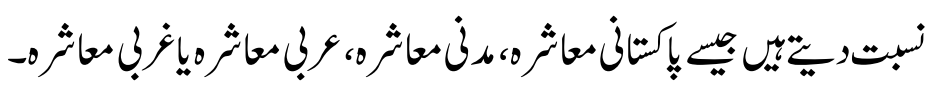

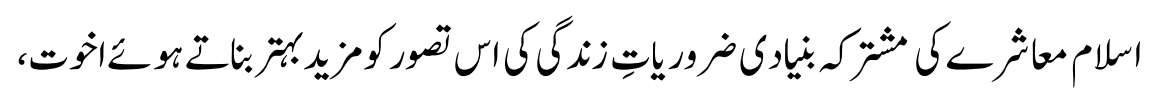

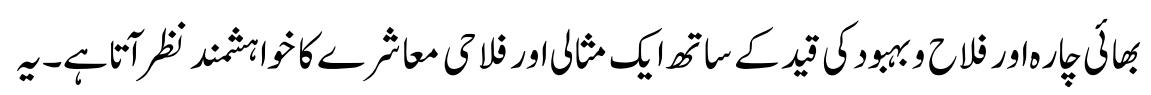

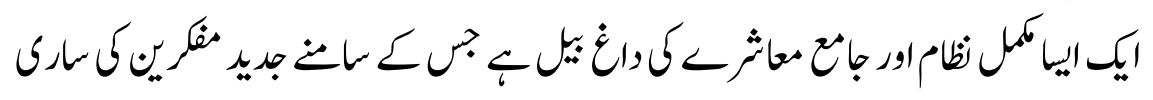

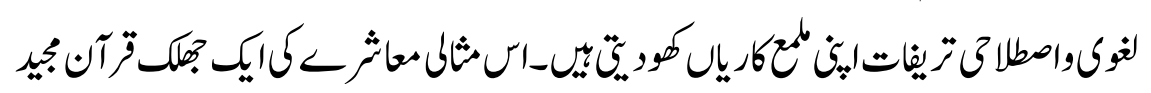

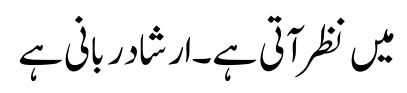

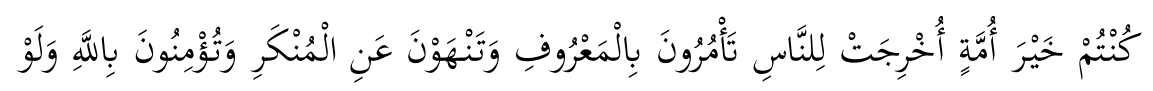

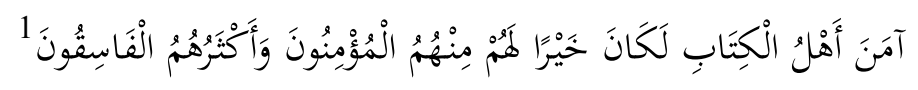

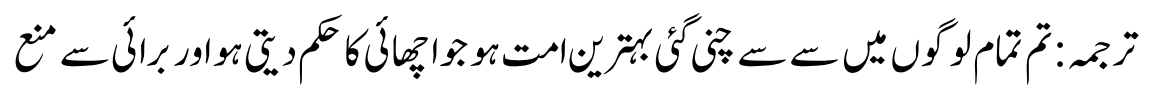

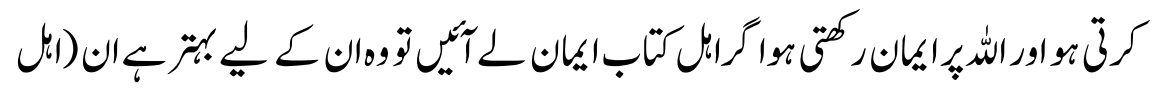

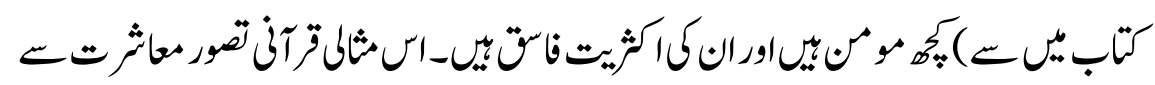

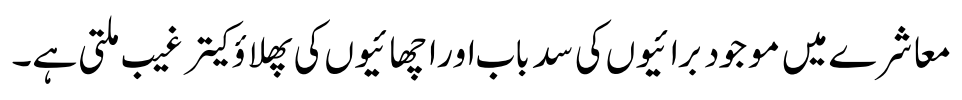

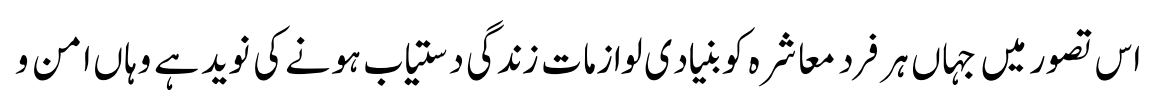

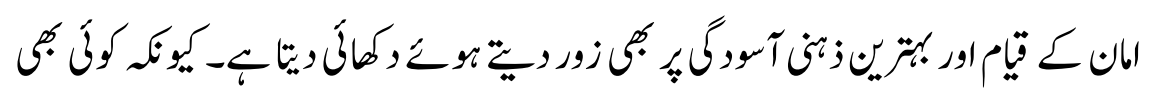

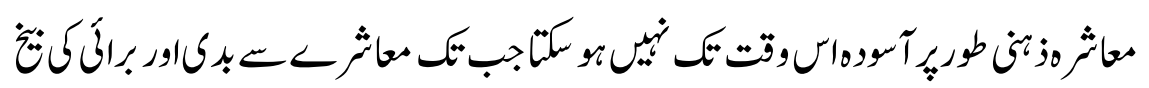

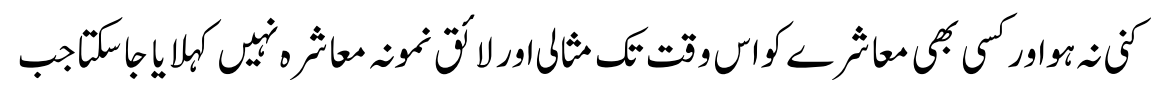

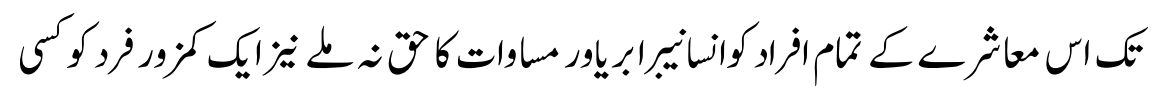

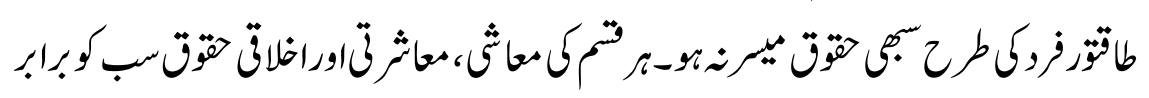

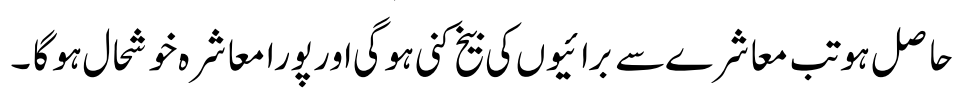




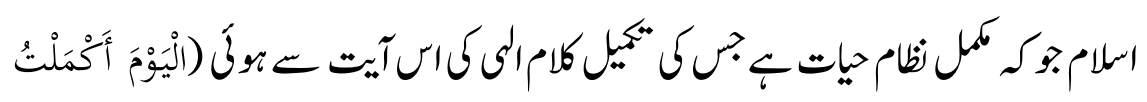

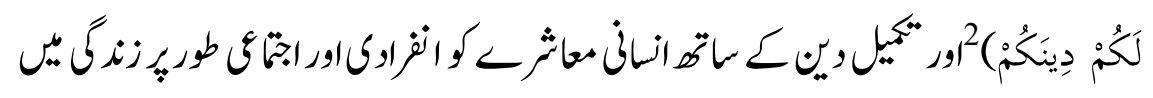

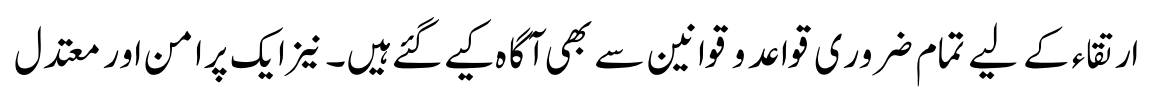

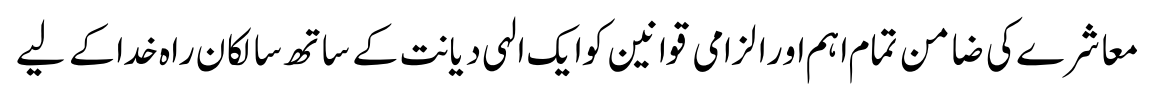

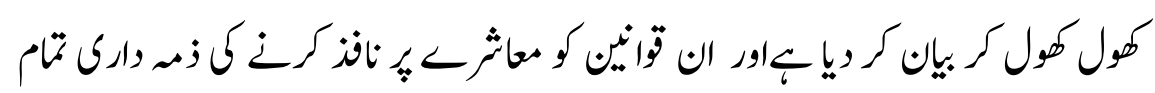

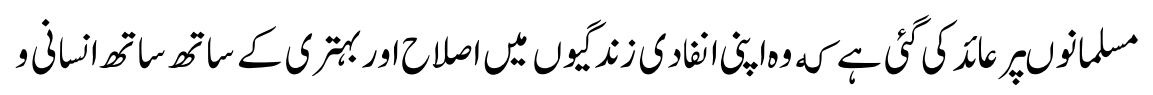

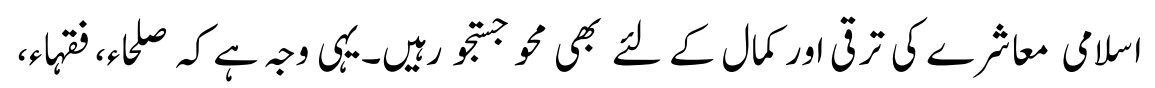

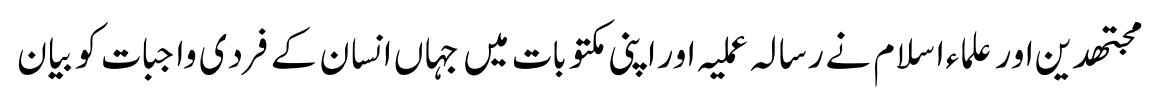

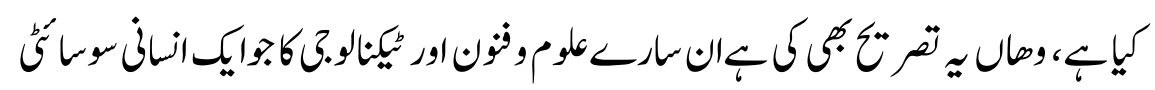

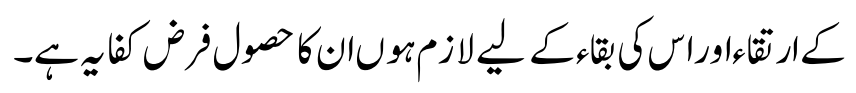

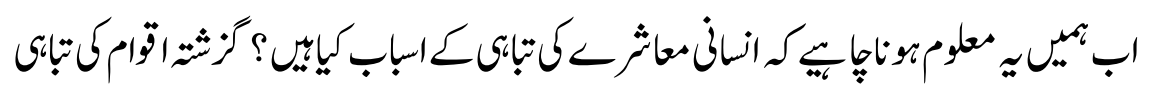

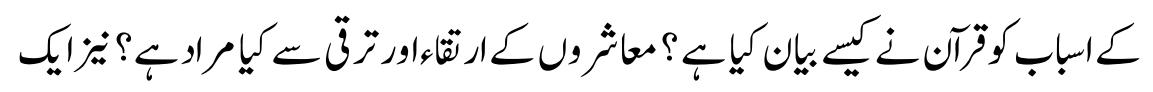

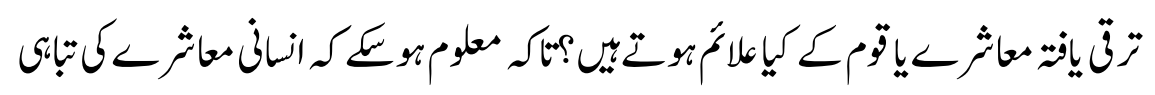

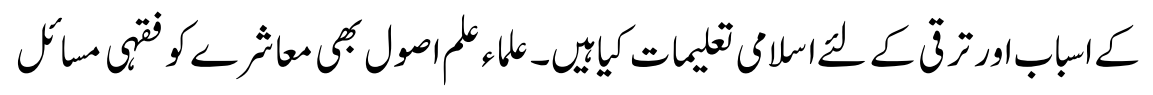

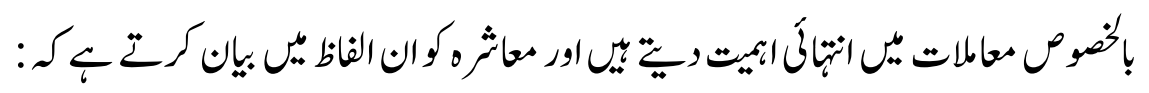

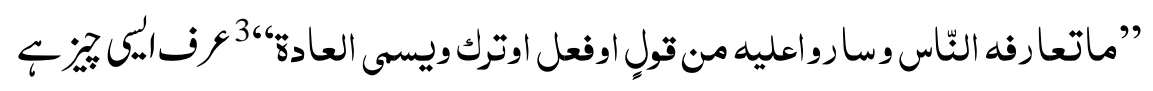

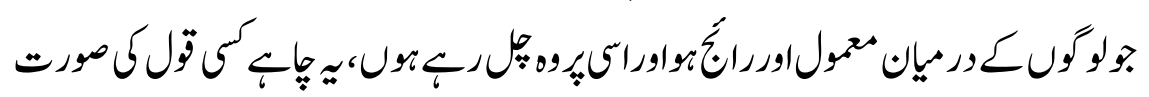

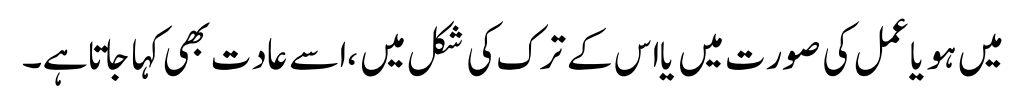
مهاثربكاقام:

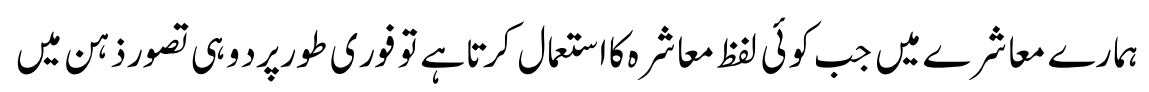

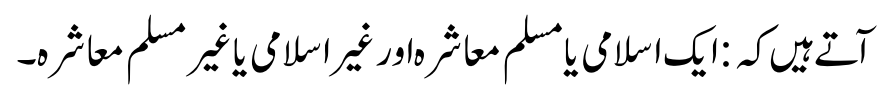




\section{نيراسلاقماثثر}

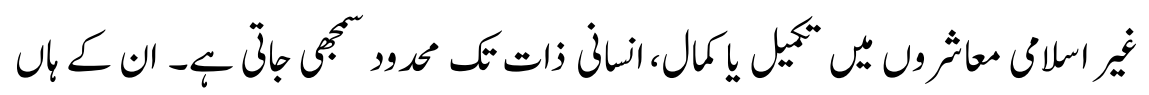

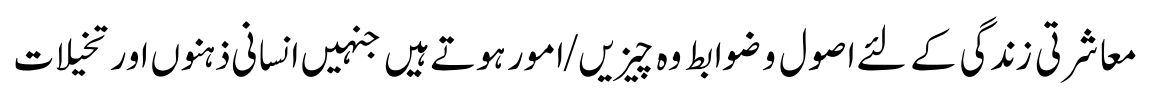

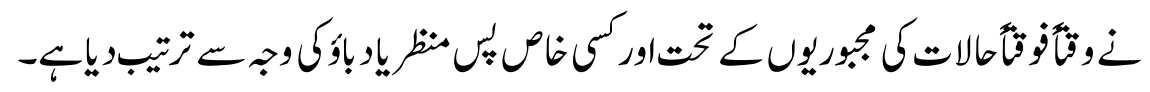

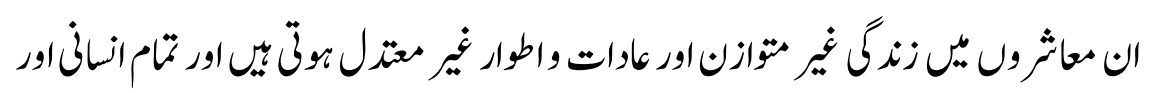

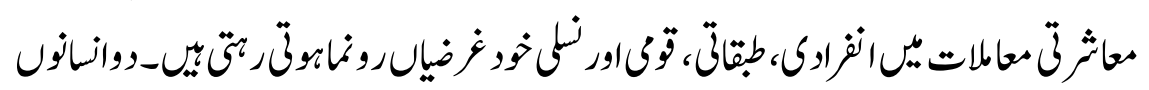

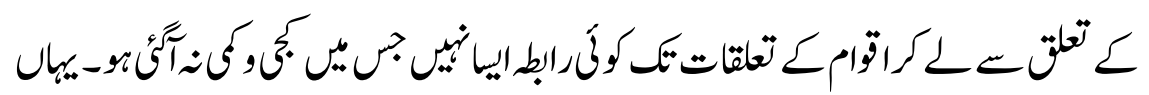

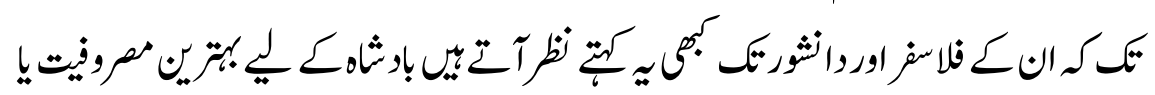

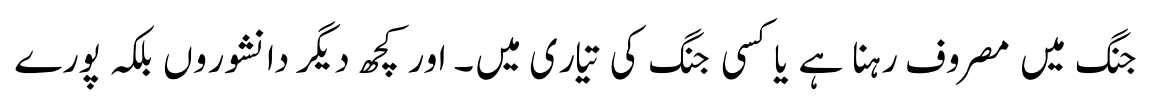

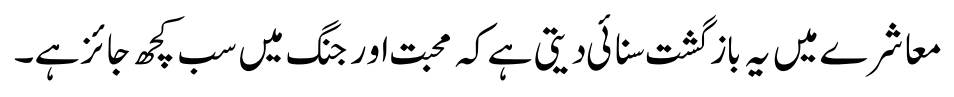

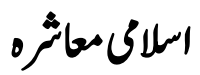

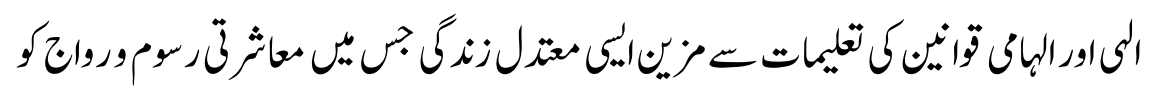

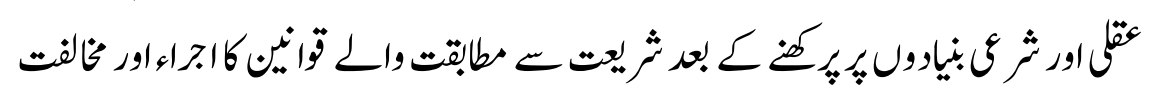

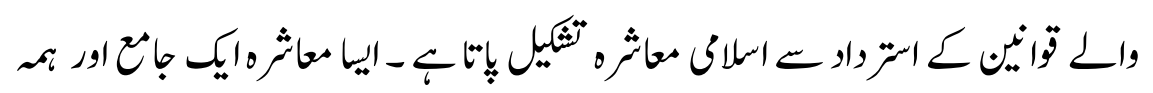

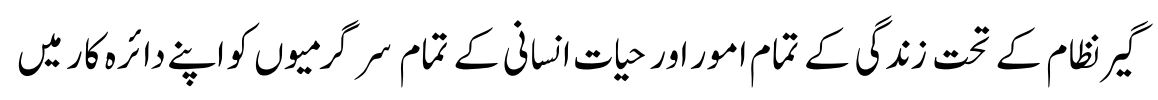

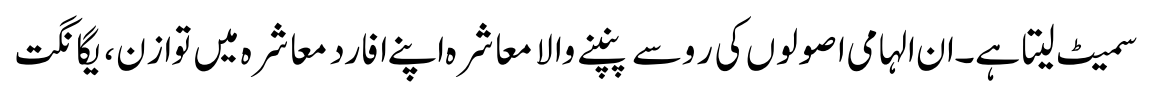

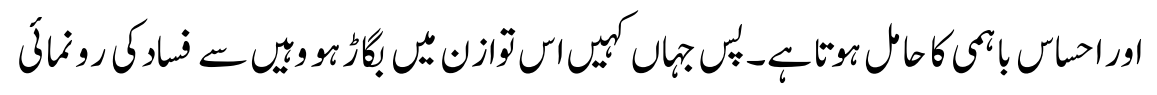

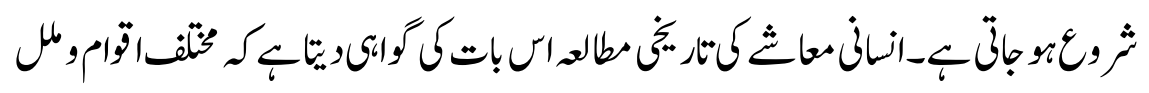

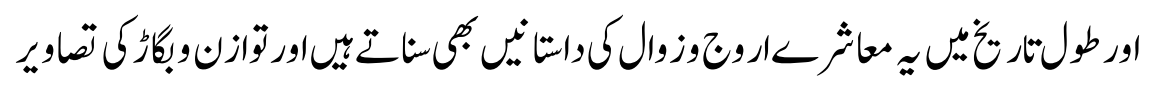

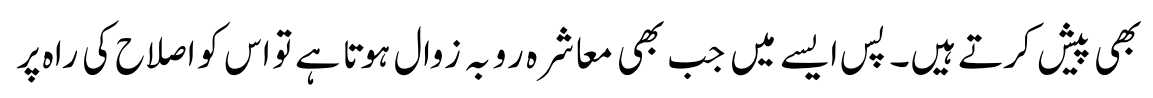




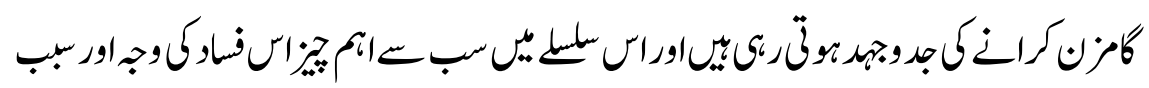
كويكمناب

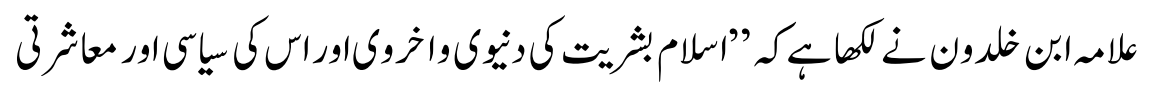

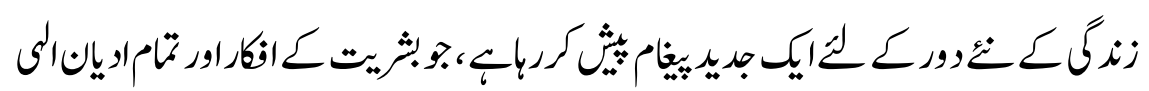

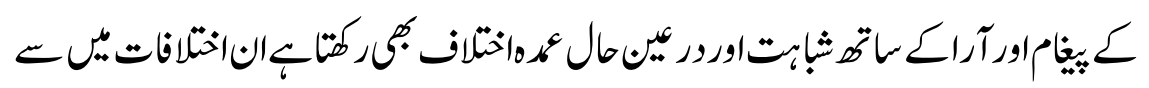

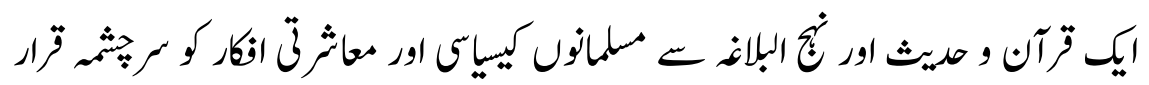
4،

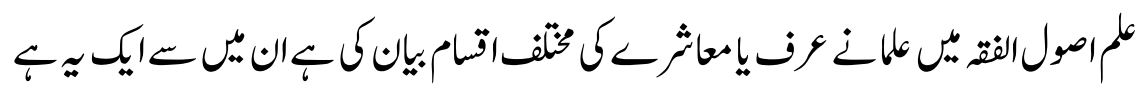

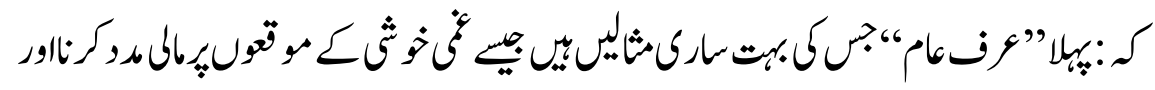

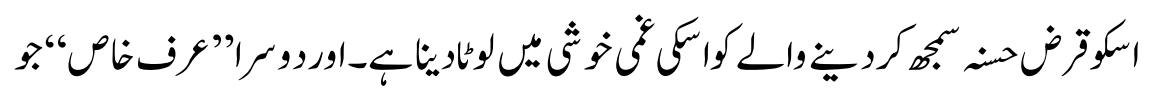

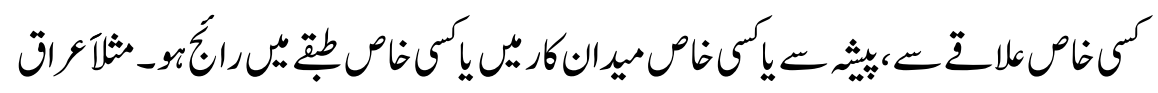

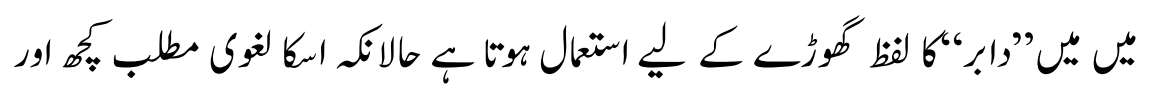

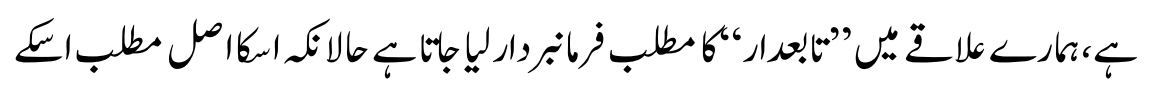

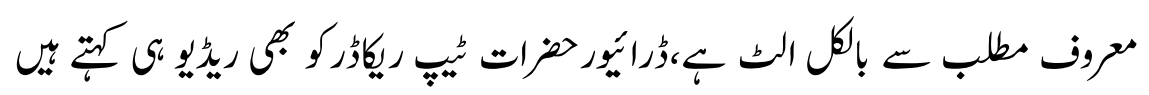

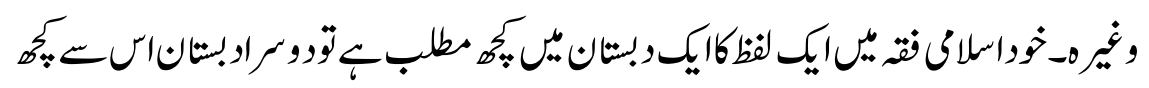

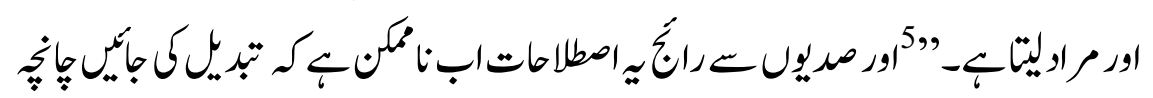

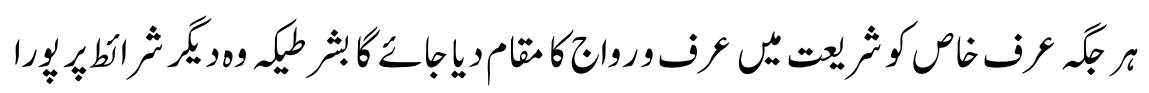
اتزنابو-

\section{كتّف مهاثر}

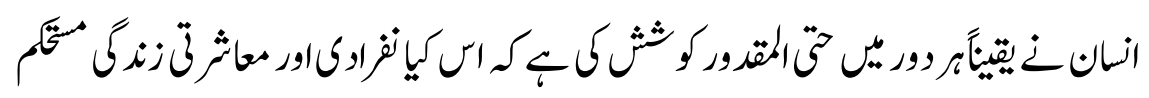

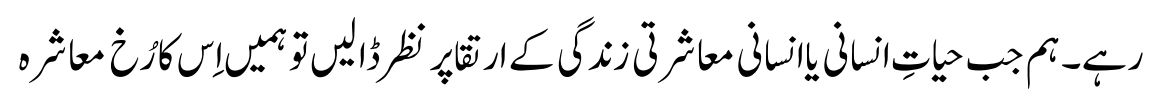

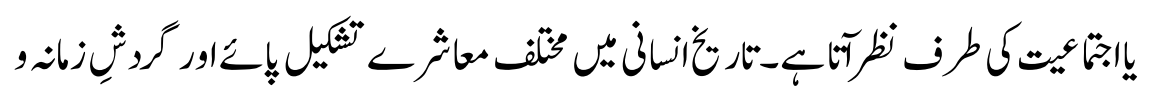




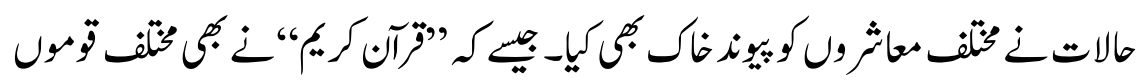

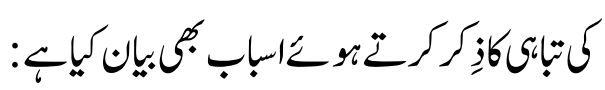

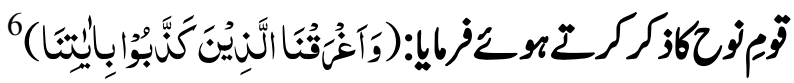

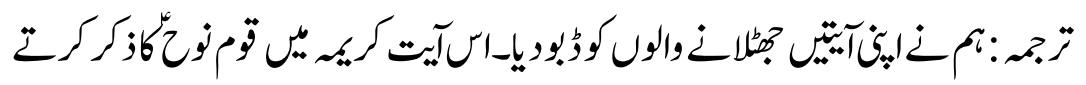

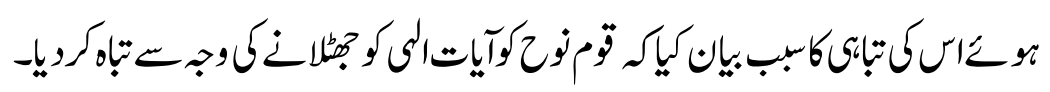

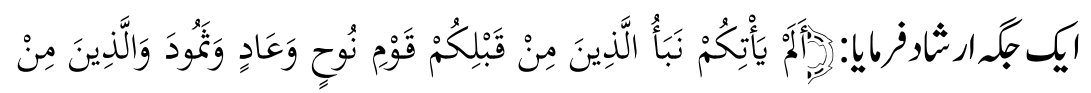

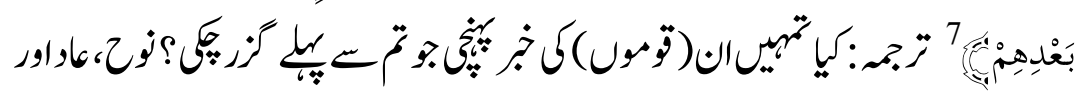

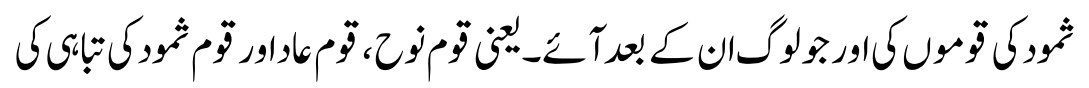

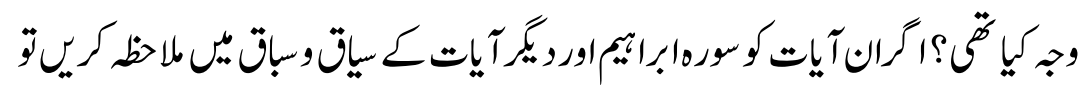

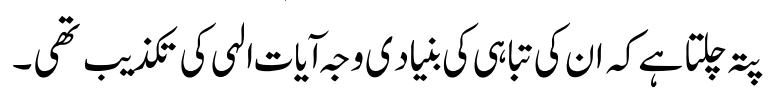

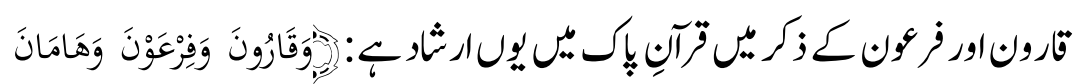

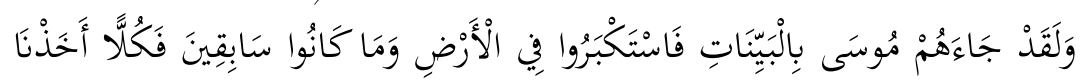

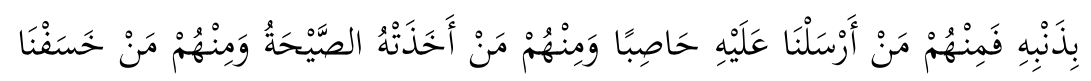

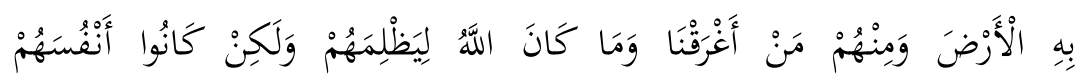

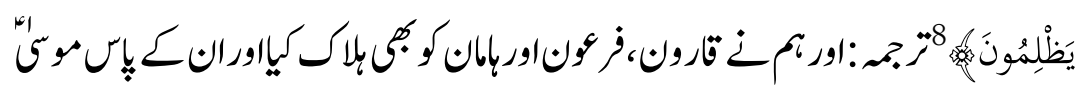

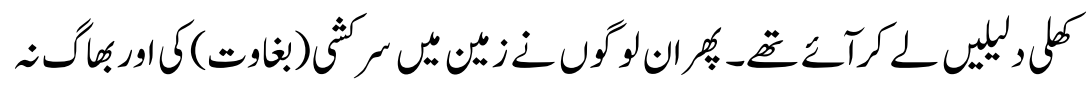

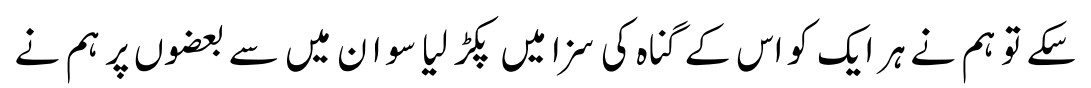

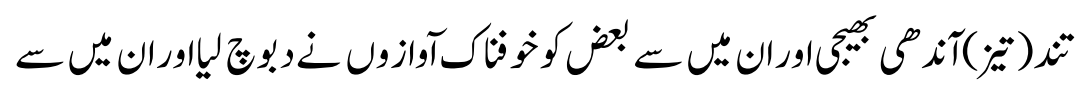

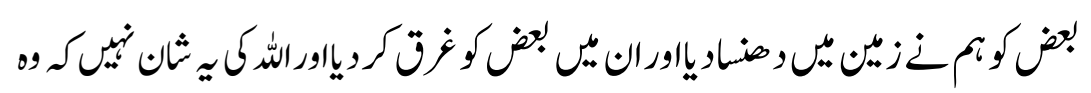

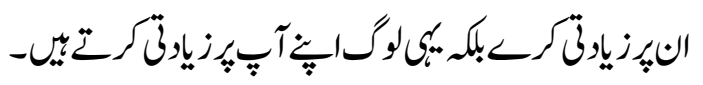




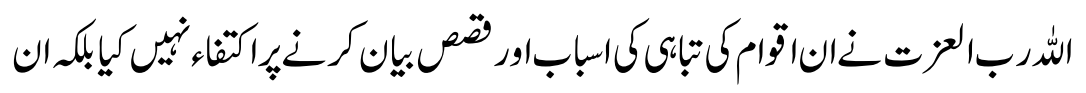

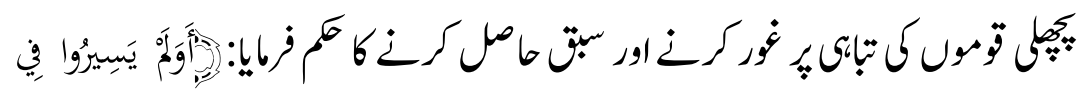

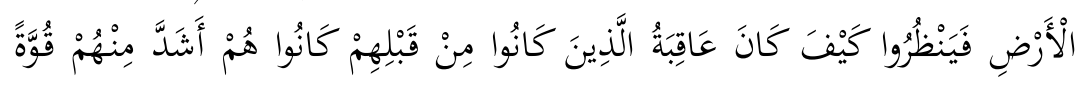

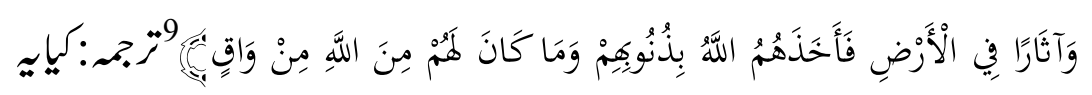

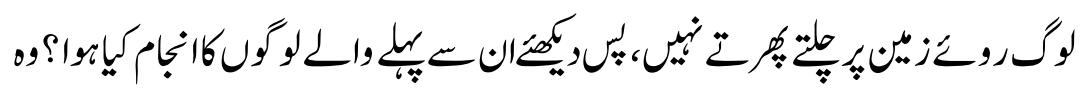

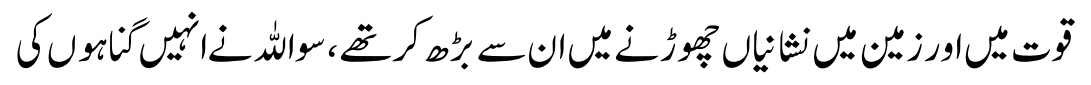

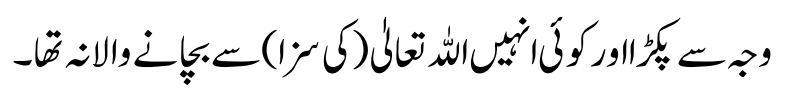

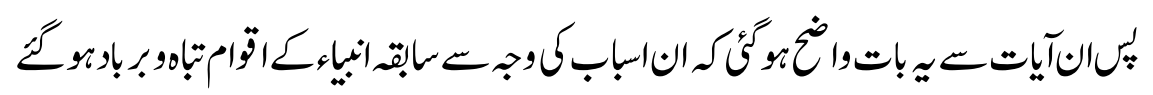

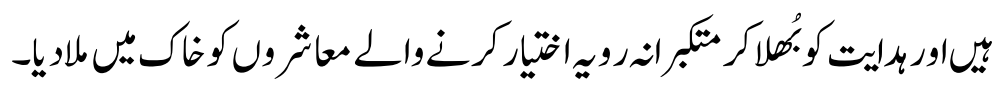

\section{ماثركعتن:}

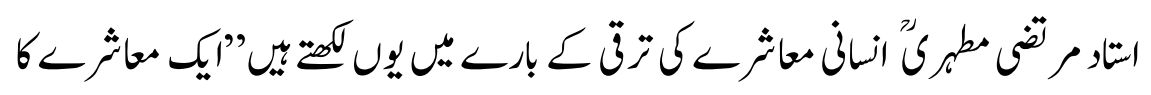

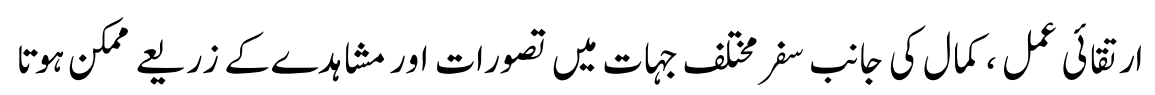

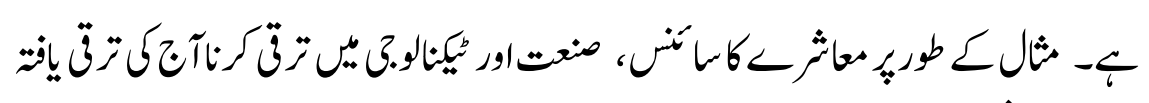

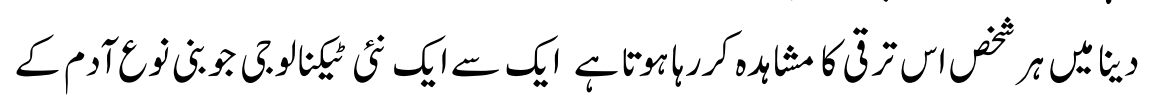

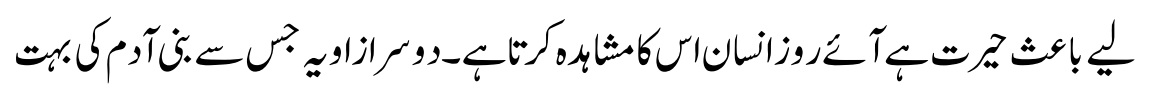

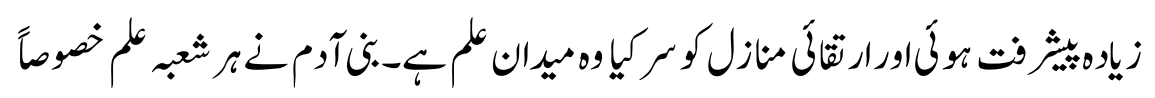

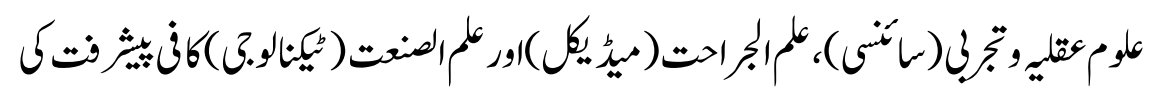

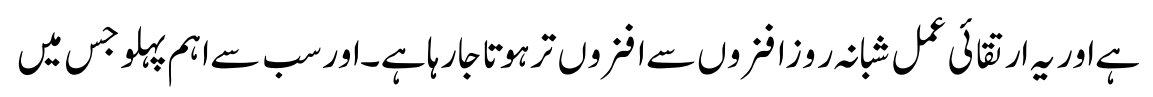

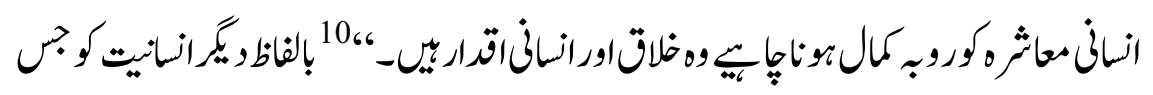

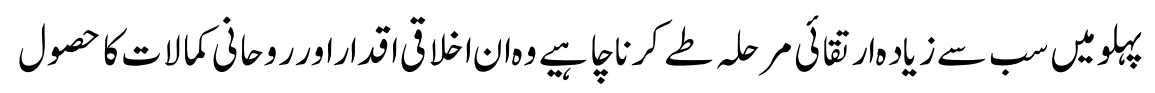

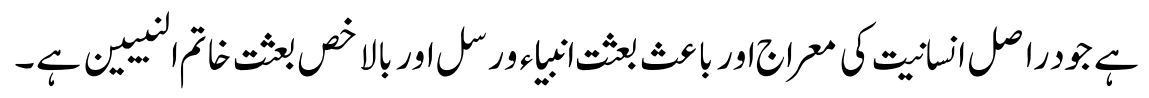




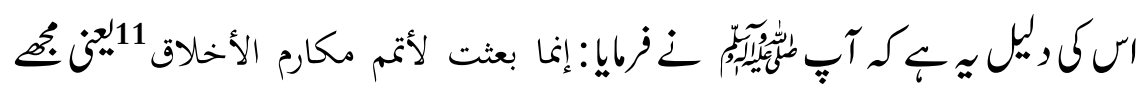

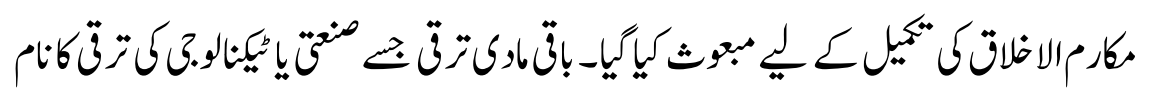

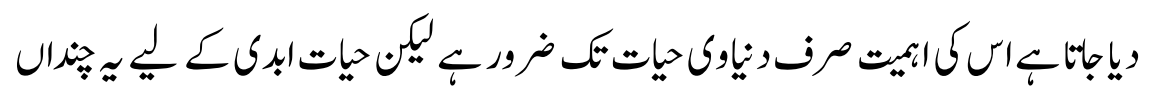

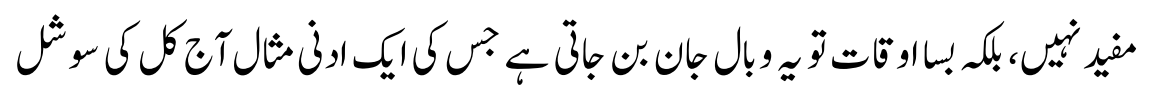

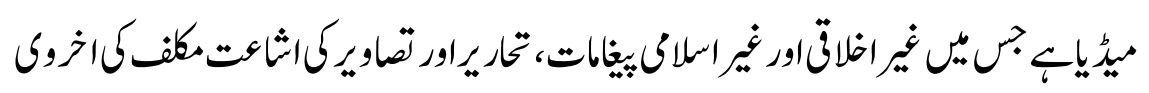

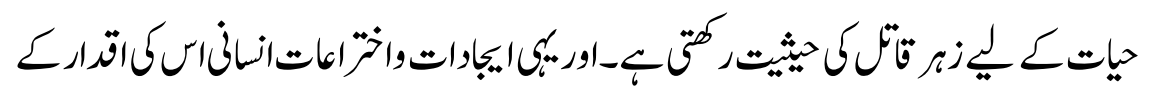

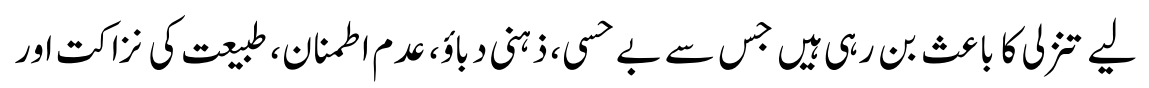

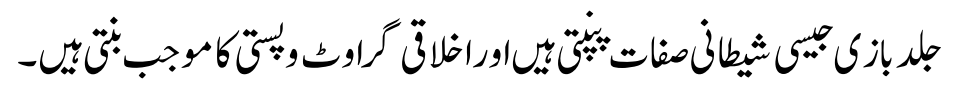

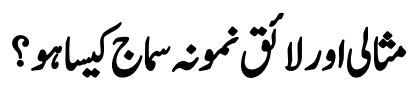

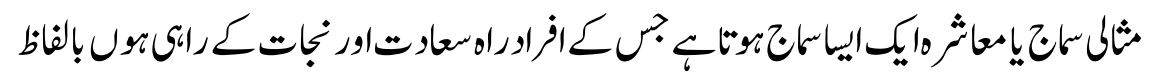

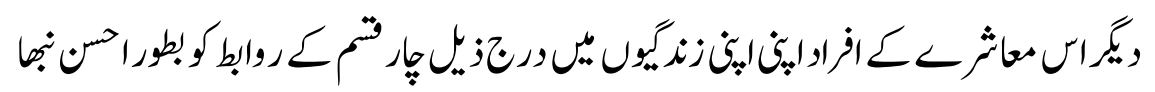

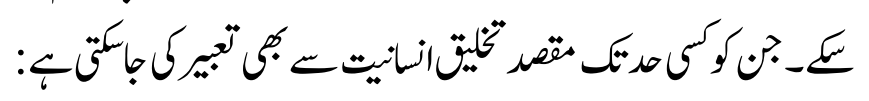

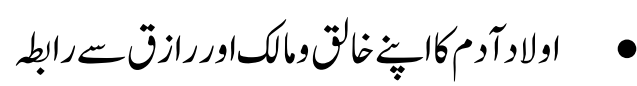

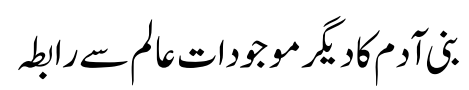

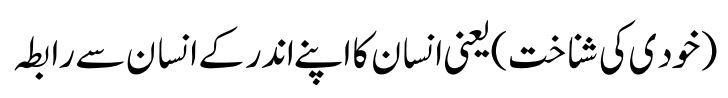

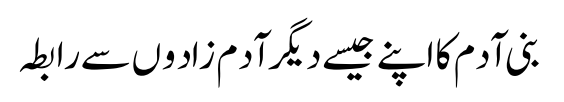

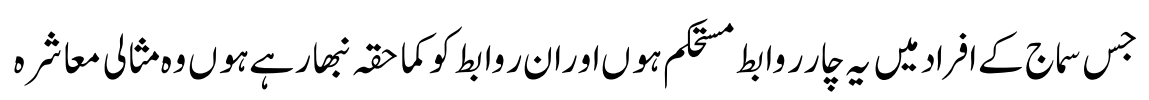

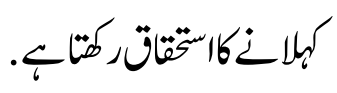

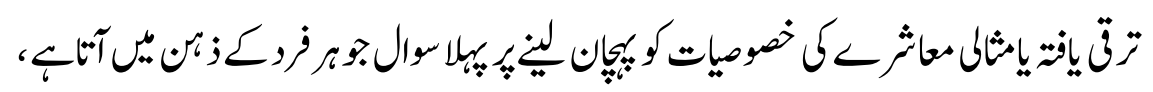

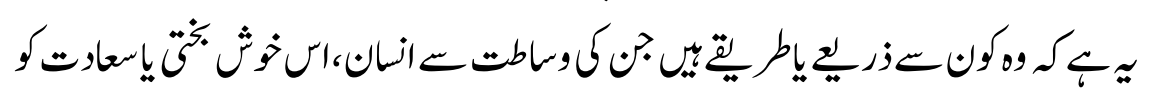

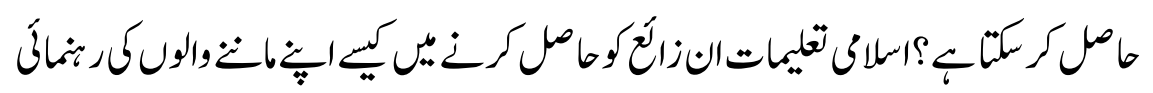




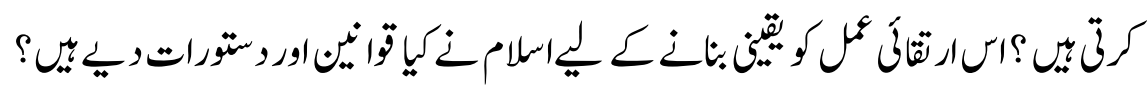

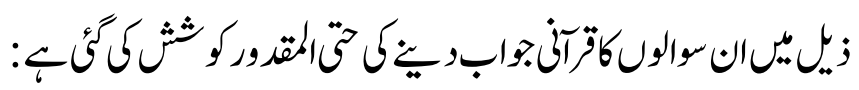

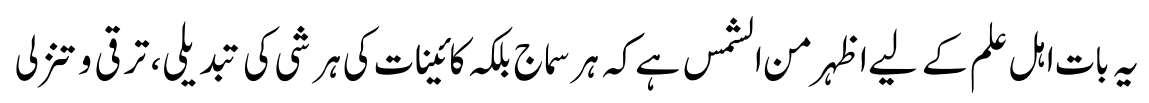

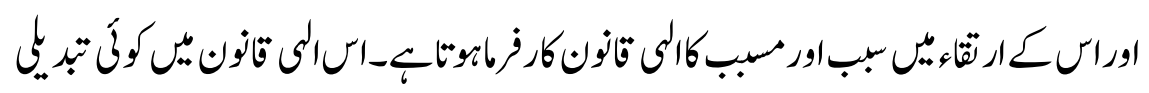

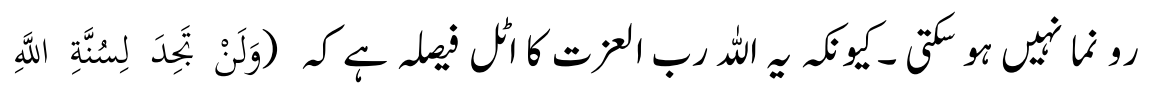

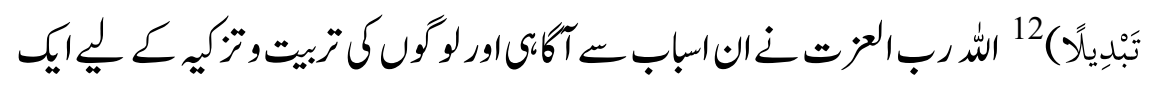

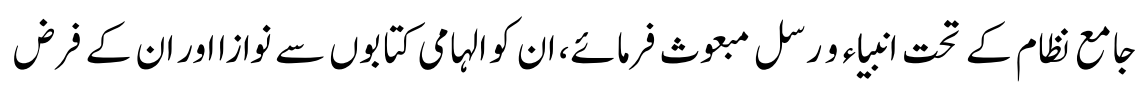

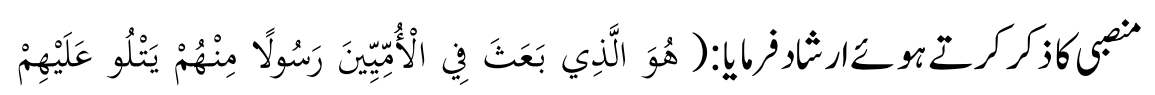

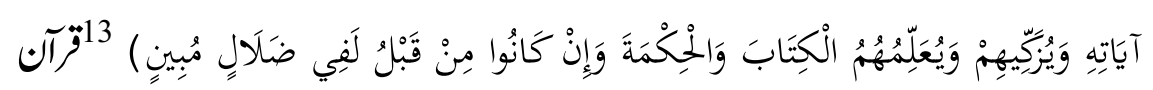

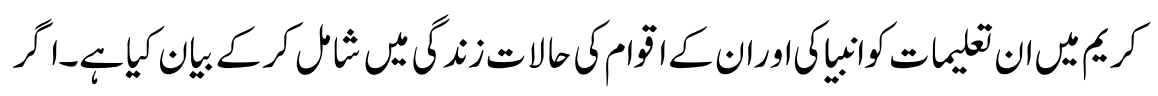

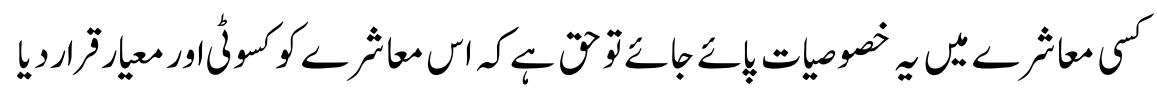

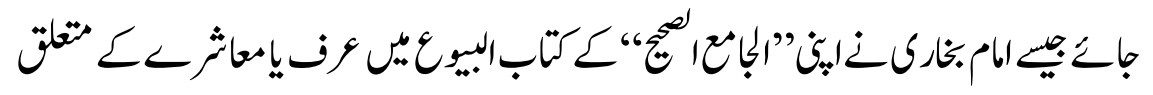

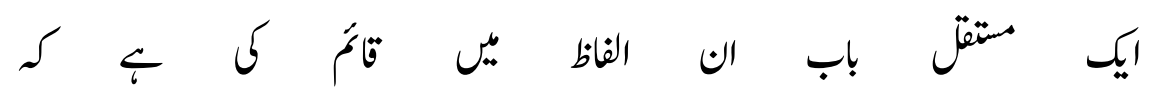

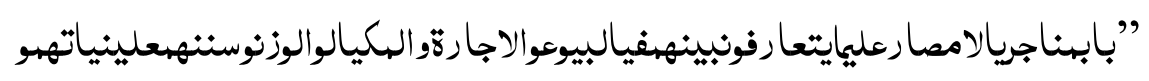

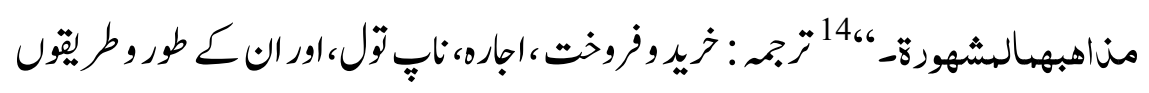

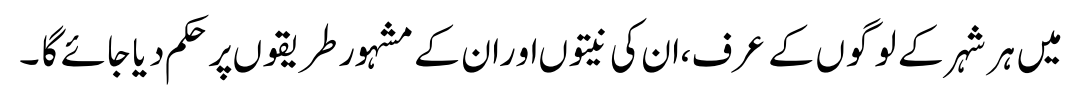

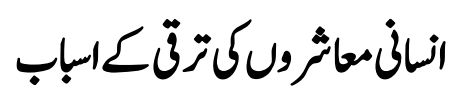

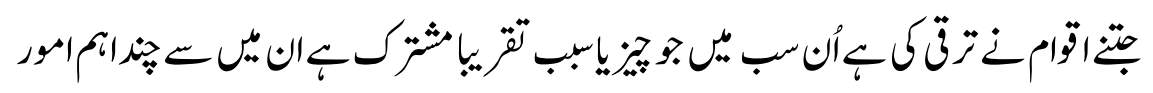
مندرنة ئيّ:

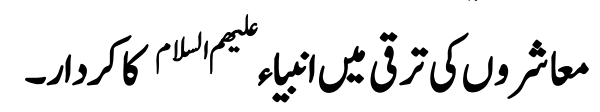




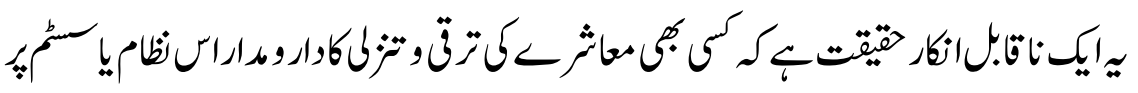

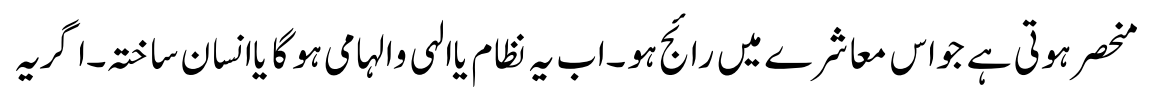

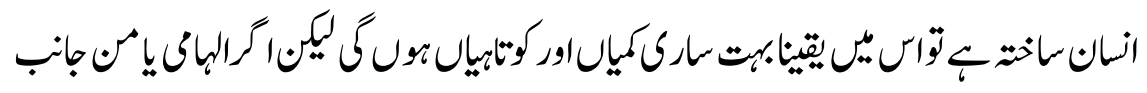

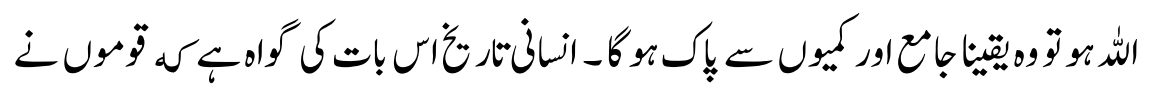

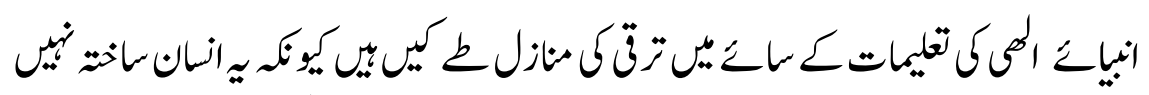

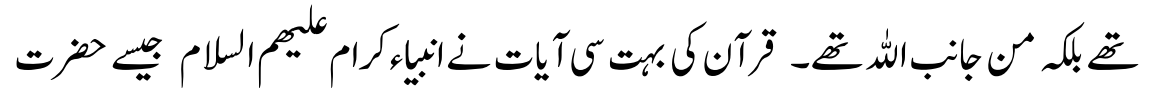

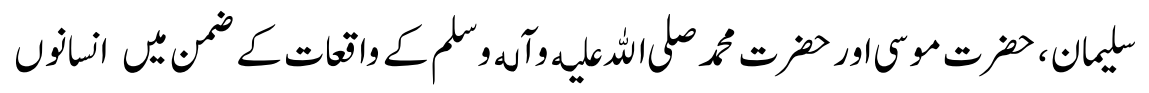

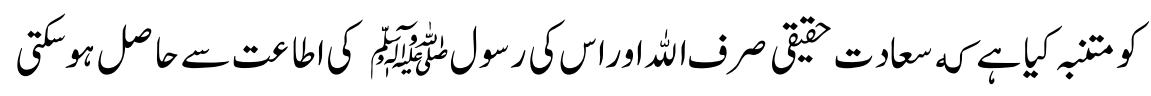

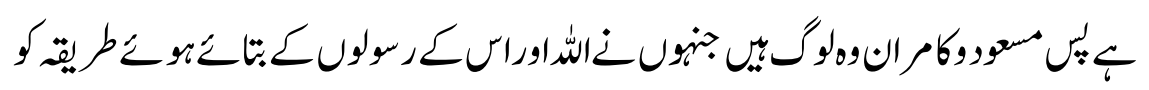

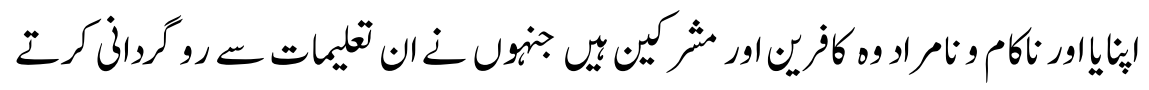

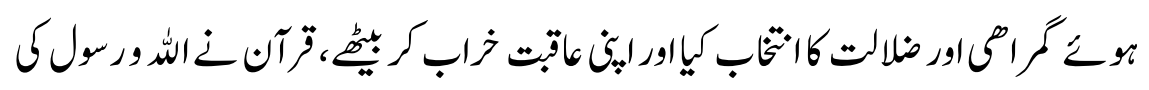

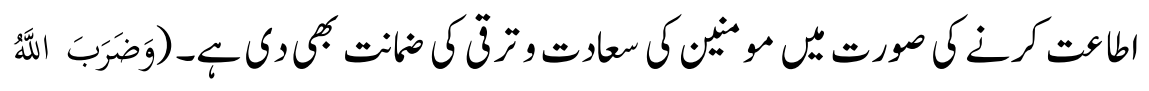

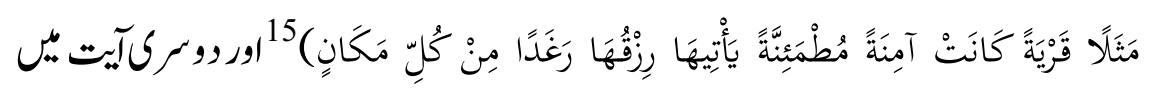

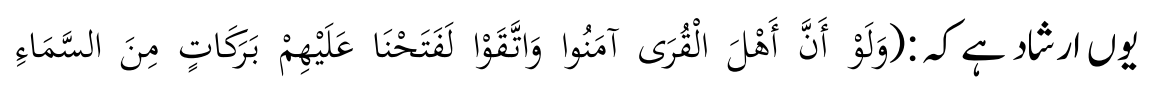

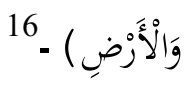

\section{علموثقانت}

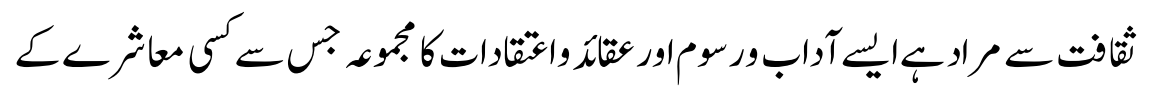

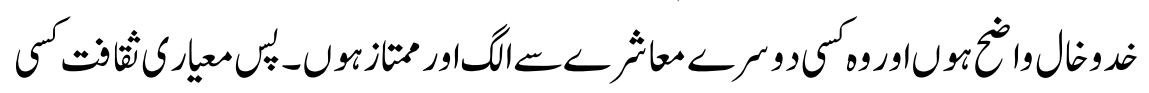

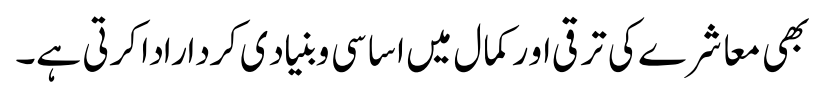

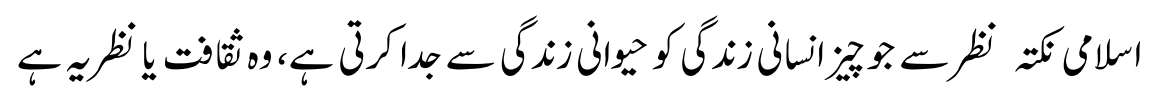

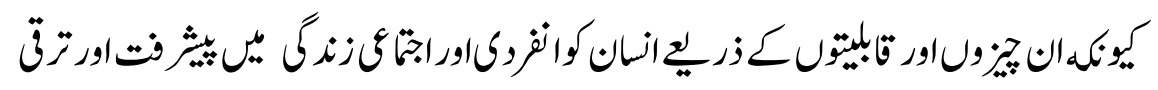




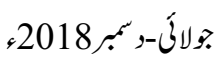

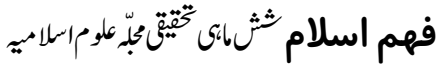

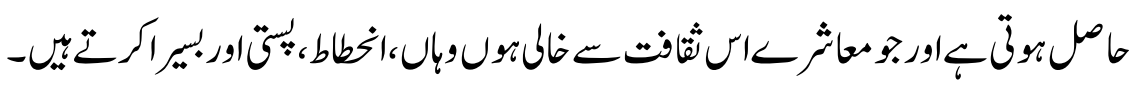

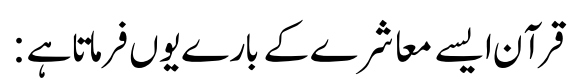

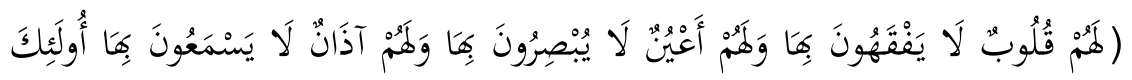

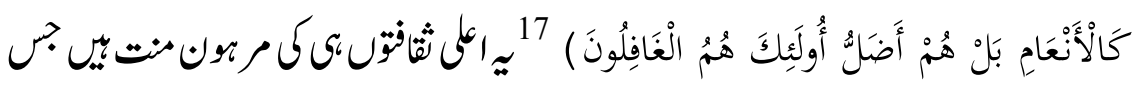

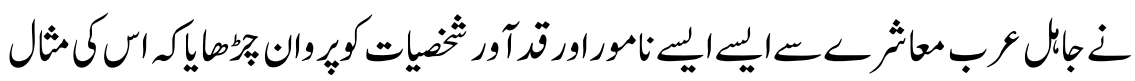

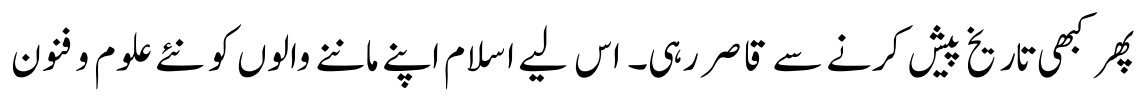

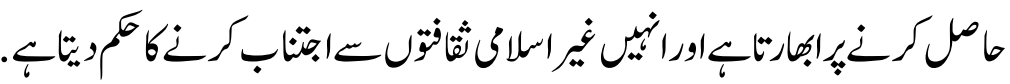

然

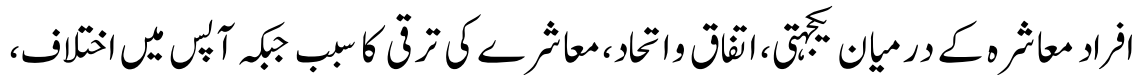

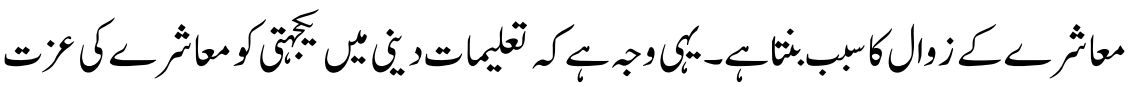
,

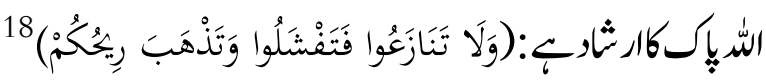

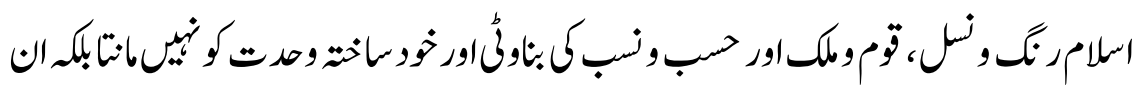

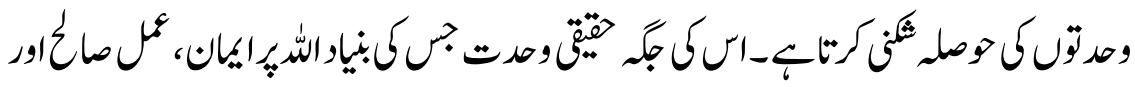

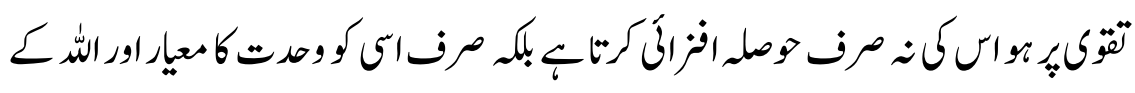

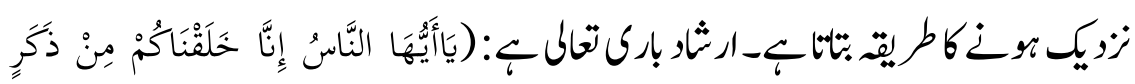

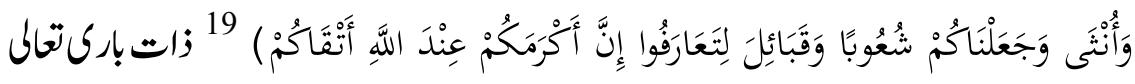

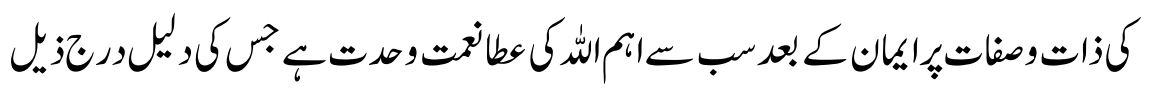

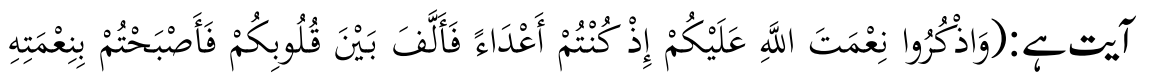

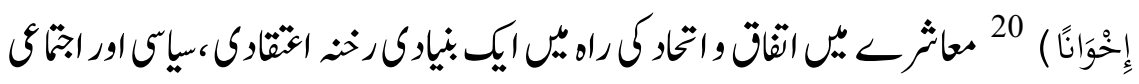

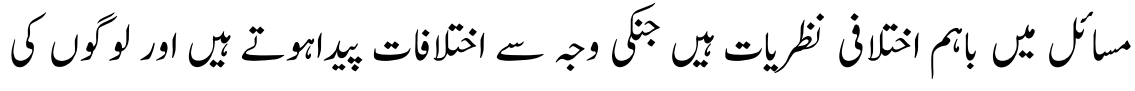

79 


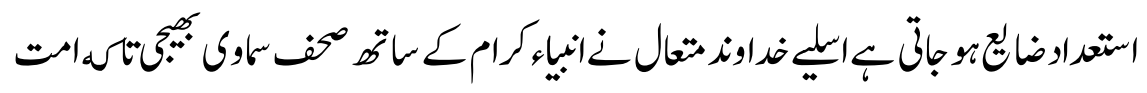

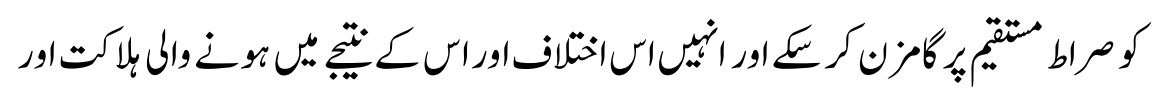

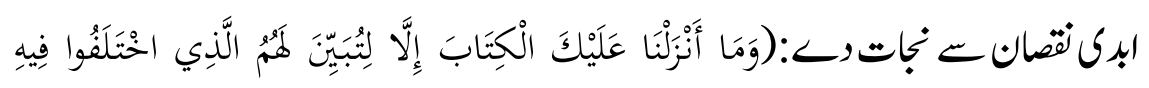

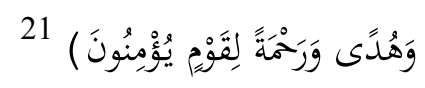

\section{عرلومساوات}

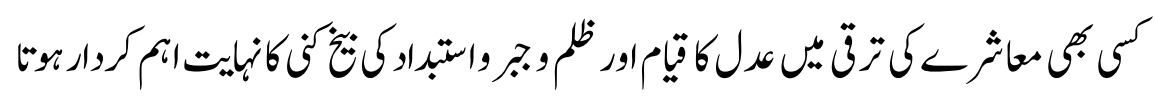

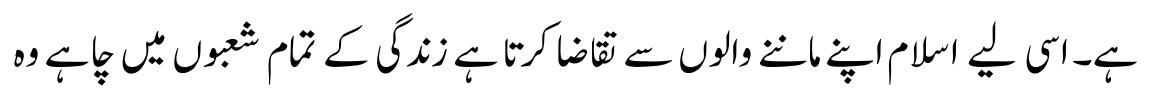

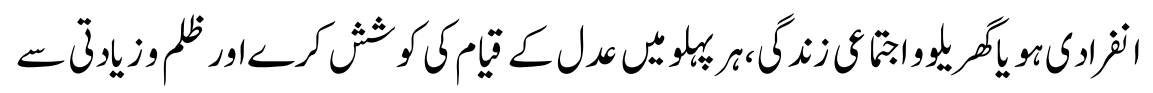

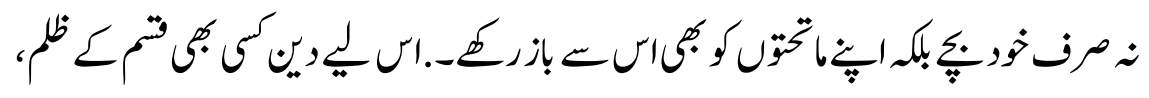

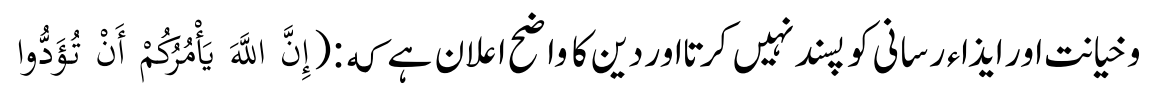

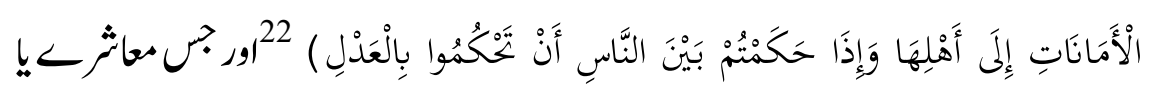

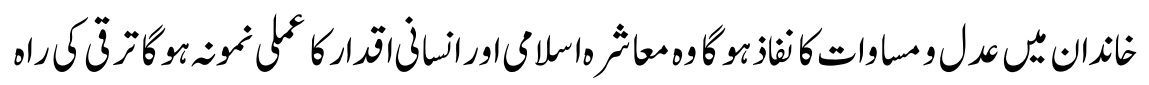

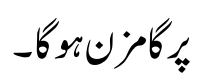

\section{قوانثن بإسدارى}

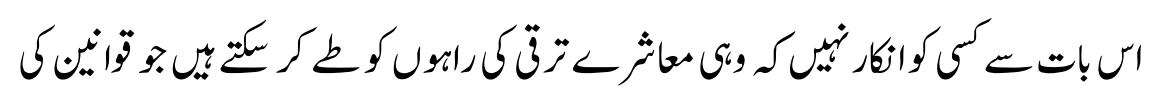

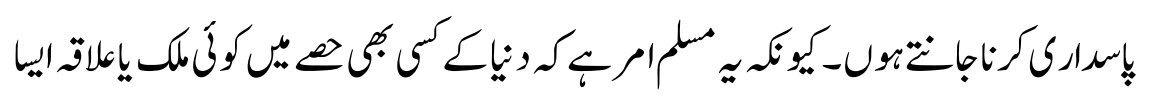

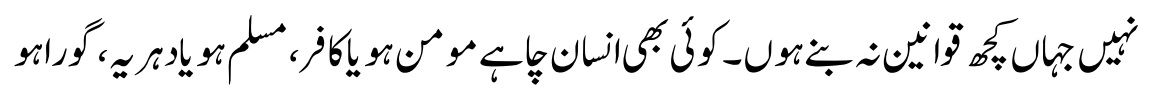

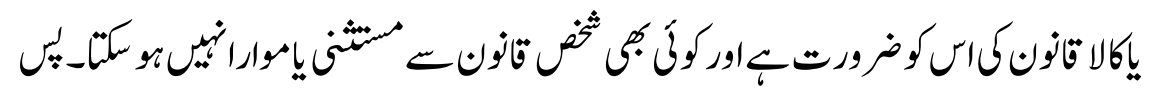

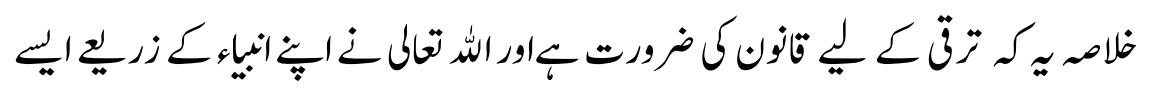

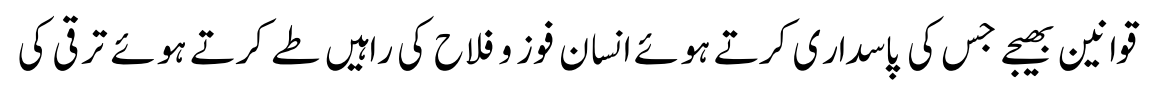

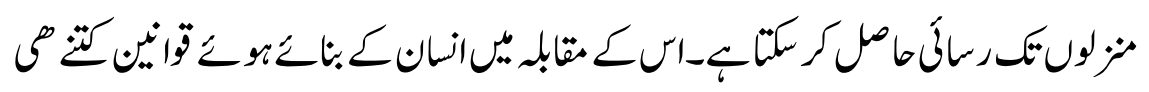




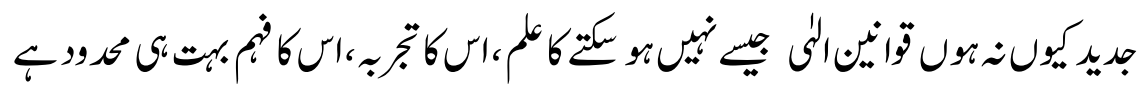

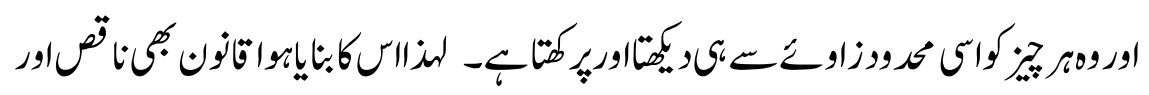

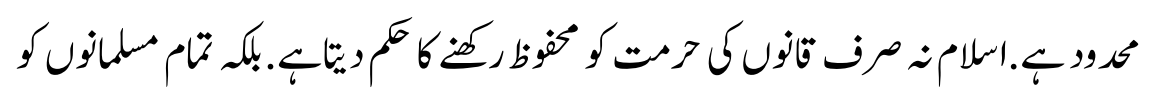

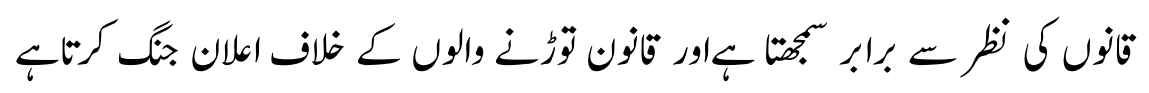

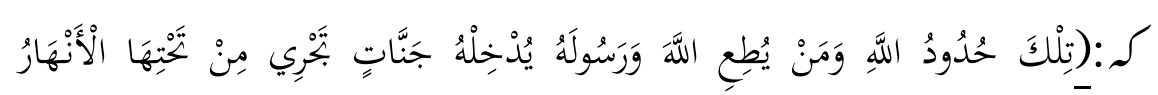

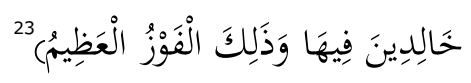

\section{مغوطقيّات}

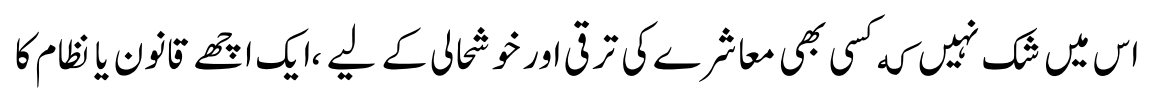

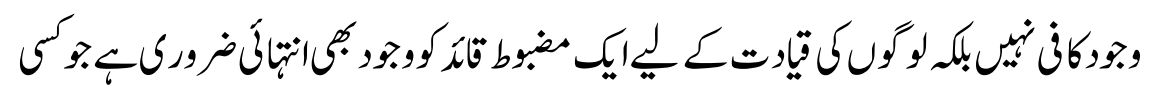

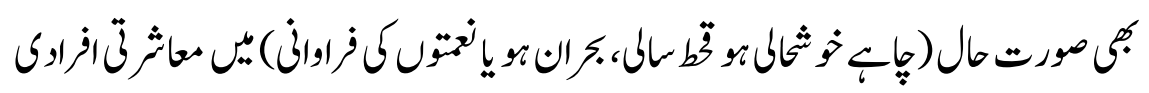

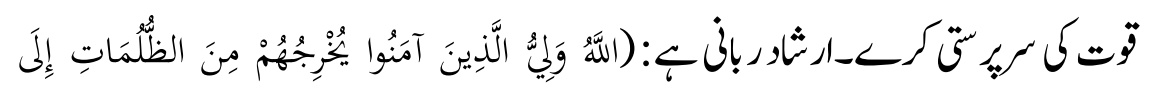

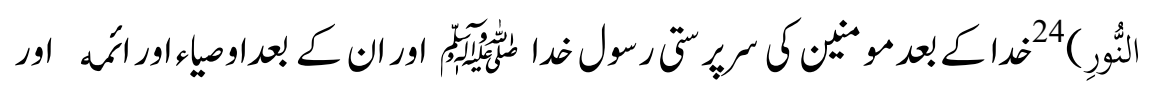

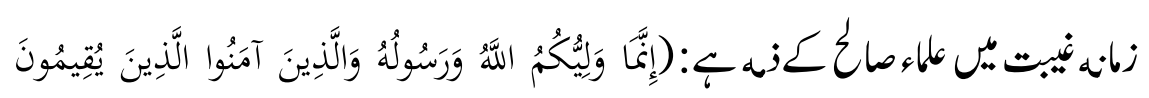

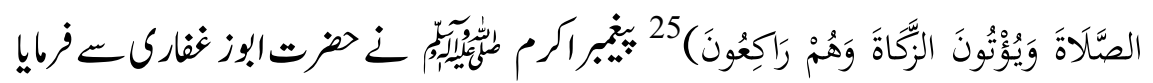

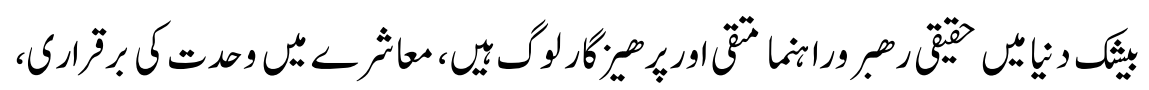

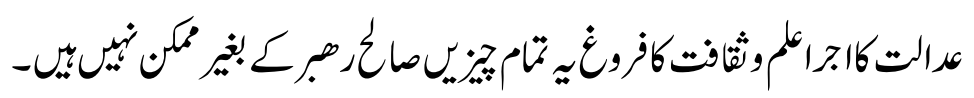

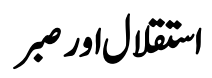

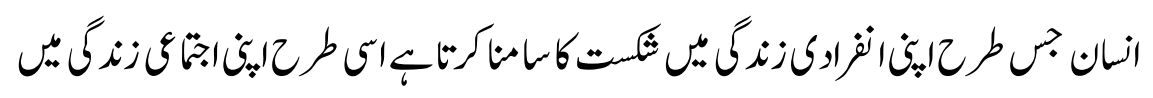

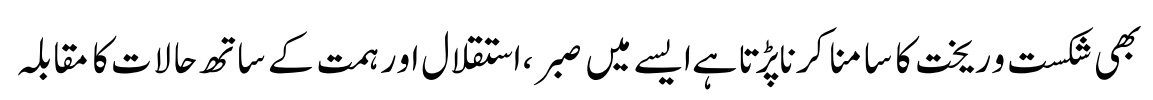

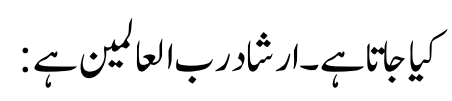




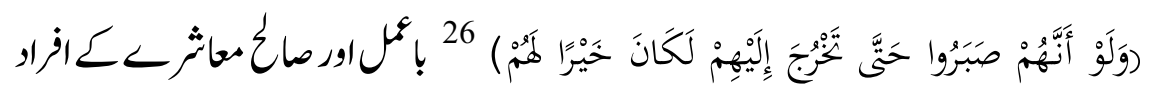

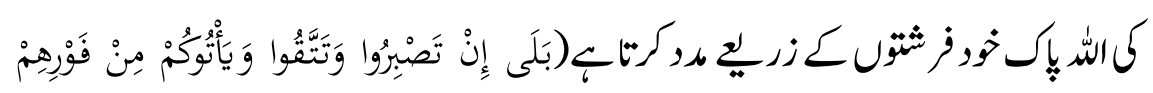

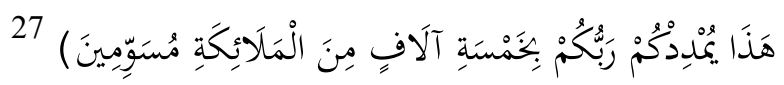

\section{انانولكورميانمجت}

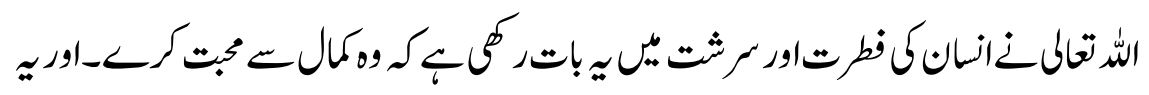

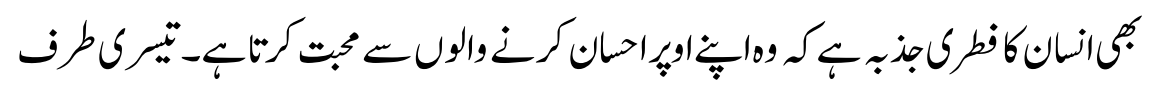

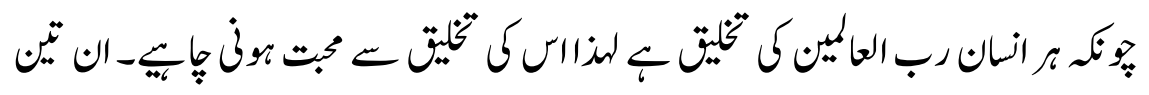

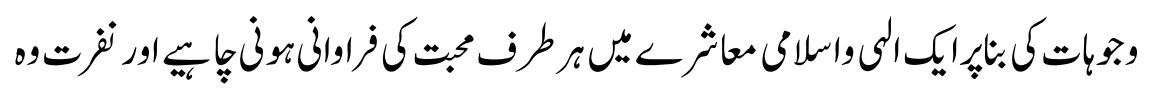

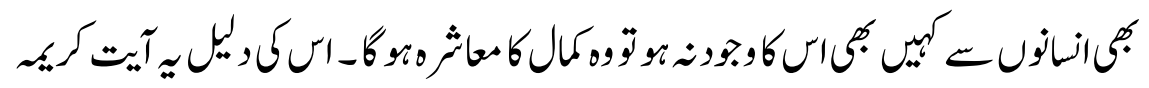

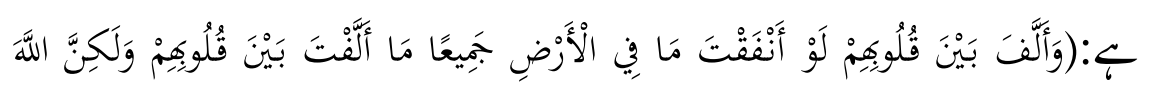

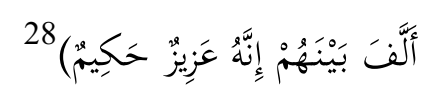

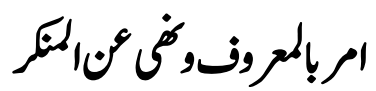

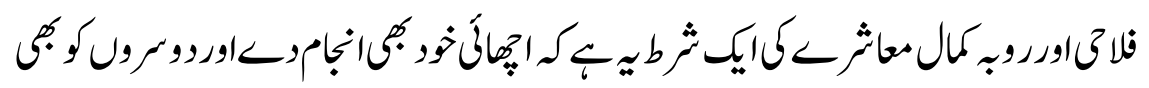

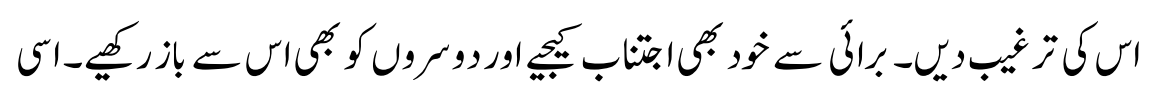

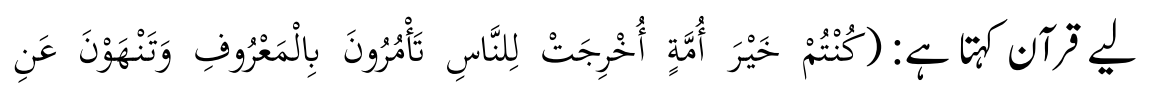

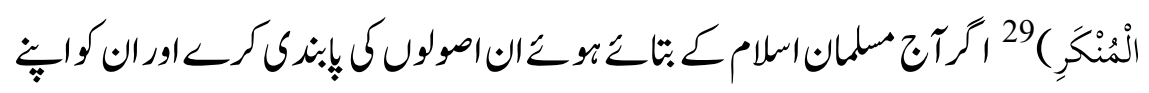

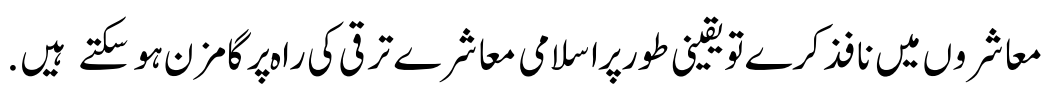

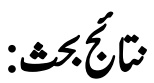

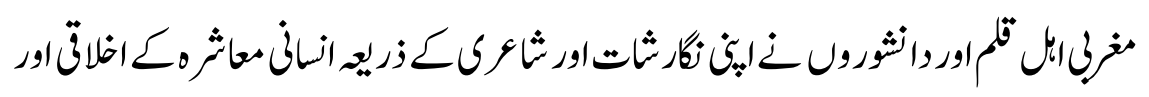

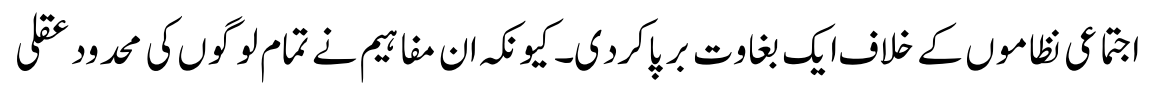




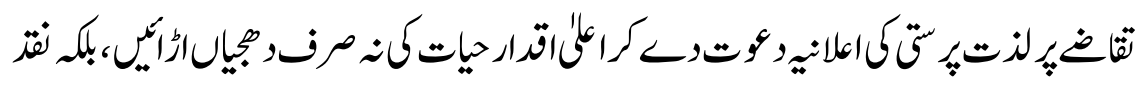

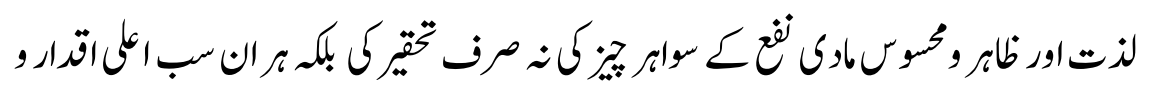

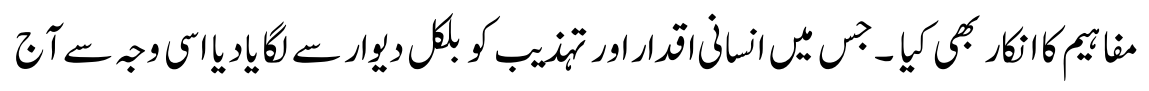

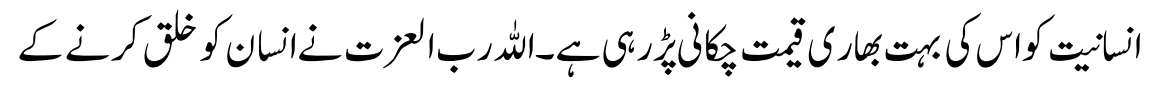

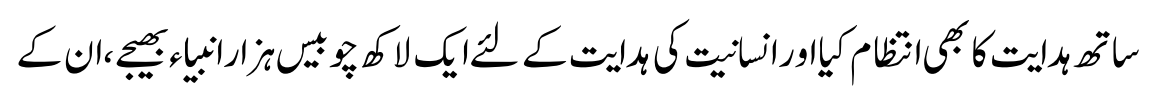

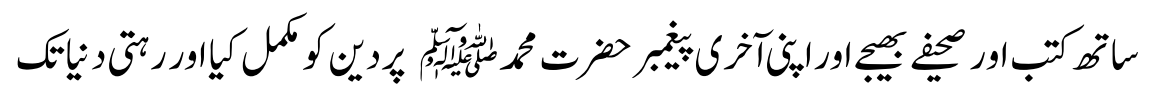

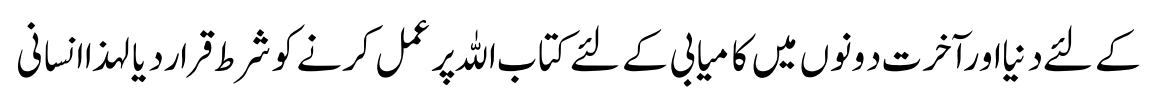

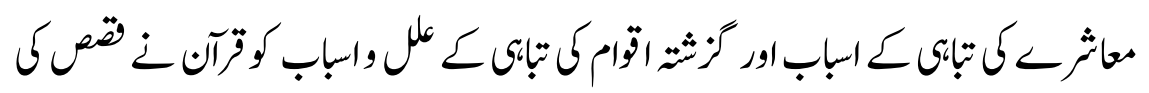

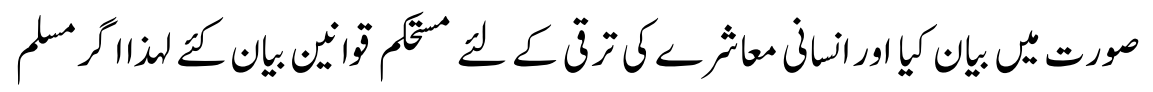

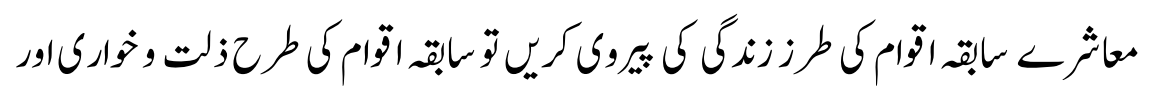

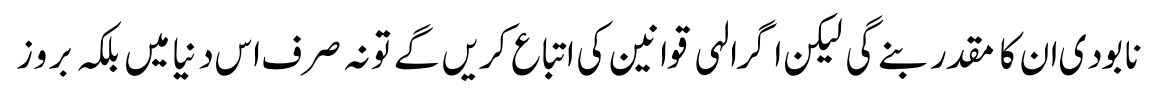

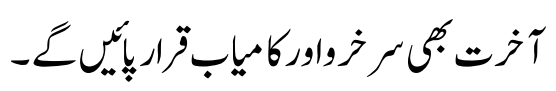

والدجات

$$
\begin{aligned}
& 1 \\
& 2
\end{aligned}
$$

3 4 5

$$
\begin{aligned}
& 6 \\
& 7 \\
& 8 \\
& 9
\end{aligned}
$$


10

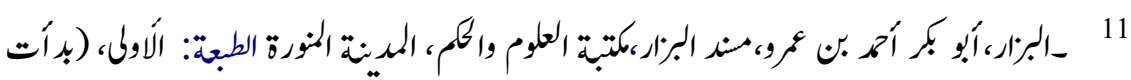

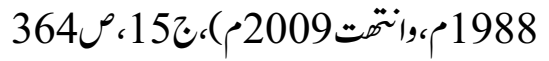

$$
\begin{aligned}
& 12 \\
& 13
\end{aligned}
$$

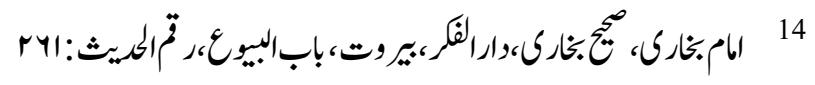

$$
\begin{aligned}
& 15 \text { سورة/انثل:114/14 } \\
& \text { 16 } \\
& 17 \\
& \text { 46/8 18 } 18 \\
& 19 \\
& 20 \\
& 21 \\
& 22 \\
& 23 \\
& 24 \\
& 25 \\
& 26 \text { سورةالمجات:ه } 27 \\
& 27 \\
& 28 \\
& 29
\end{aligned}
$$

